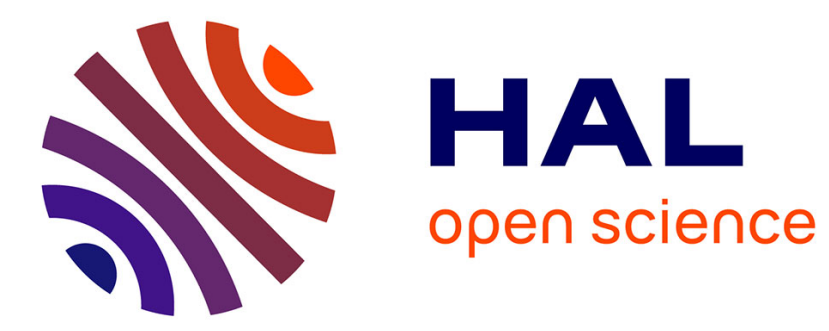

\title{
Impact of the material on the thermal behaviour of heat exchangers-reactors
}

Laurène Despènes, Sébastien Elgue, Christophe Gourdon, Michel Cabassud

\section{To cite this version:}

Laurène Despènes, Sébastien Elgue, Christophe Gourdon, Michel Cabassud. Impact of the material on the thermal behaviour of heat exchangers-reactors. Chemical Engineering and Processing: Process Intensification, 2012, vol. 52, pp. 102-111. 10.1016/j.cep.2011.11.005 . hal-00878793

\section{HAL Id: hal-00878793 \\ https://hal.science/hal-00878793}

Submitted on 31 Oct 2013

HAL is a multi-disciplinary open access archive for the deposit and dissemination of scientific research documents, whether they are published or not. The documents may come from teaching and research institutions in France or abroad, or from public or private research centers.
L'archive ouverte pluridisciplinaire $\mathbf{H A L}$, est destinée au dépôt et à la diffusion de documents scientifiques de niveau recherche, publiés ou non, émanant des établissements d'enseignement et de recherche français ou étrangers, des laboratoires publics ou privés. 


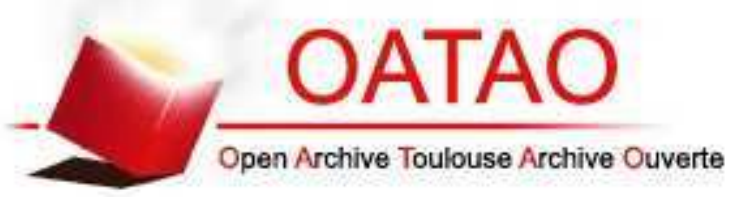

\section{Open Archive TOULOUSE Archive Ouverte (OATAO)}

OATAO is an open access repository that collects the work of Toulouse researchers and makes it freely available over the web where possible.

This is an author-deposited version published in : http://oatao.univ-toulouse.fr/ Eprints ID : 9977

To link to this article : DOI:10.1016/j.cep.2011.11.005

URL : http://dx.doi.org/10.1016/j.cep.2011.11.005

To cite this version : Despènes, Laurène and Elgue, Sébastien and Gourdon, Christophe and Cabassud, Michel. Impact of the material on the thermal behaviour of heat exchangers-reactors. (2012) Chemical Engineering and Processing, vol. 52 . pp. 102-111. ISSN 0255-2701

Any correspondance concerning this service should be sent to the repository administrator: staff-oatao@ listes-diff.inp-toulouse.fr 


\title{
Impact of the material on the thermal behaviour of heat exchangers-reactors
}

\author{
Laurène Despènes $^{\mathrm{a}, \mathrm{b}}$, Sébastien Elgue ${ }^{\mathrm{a}, \mathrm{b}}$, Christophe Gourdon ${ }^{\mathrm{a}, \mathrm{b}, *}$, Michel Cabassud ${ }^{\mathrm{a}, \mathrm{b}}$ \\ a Université de Toulouse, INPT, UPS, Laboratoire de Génie Chimique, 4, Allée Emile Monso, F-31432 Toulouse, France \\ b CNRS, Laboratoire de Génie Chimique, F-31432 Toulouse, France
}

\begin{abstract}
A B S T R A C T
In the field of Process Intensification, manufacturers offer many technologies of heat exchanger-reactors which differ in the design, the nature of the material and the range of operating conditions. Such systems combine continuous operation with strongly coupled features of heat transfer, hydrodynamics, mixing, mass transfer and reaction that makes the choice of the optimal solution a difficult one. The present paper offers a comparison and a characterisation of heat exchanger-reactors manufactured in different materials: stainless steel and silicon carbide for the process plates, aluminium, stainless steel and silicon carbide for the utility plates. The results underline the advantages and drawbacks of each material and the associated impact on the control of industrial applications and, in particular, on the safety aspects.
\end{abstract}

Keywords:

Process Intensification

Heat exchanger-reactor

Clean and safe process

Silicon carbide equipments

\section{Introduction}

In the field of fine chemical or pharmaceutical manufacturing most processes are operated in a batch or a semi-batch mode, generally in stirred tank reactors. These are particularly convenient because of their reliability and flexibility. Nevertheless, as these processes are limited in terms of transfer, productivity and safety $[1,2]$, there is increasing interest in moving towards continuous reactors and Process Intensification [3,4].

Accordingly, one technological solution proposed by various equipment suppliers is based on the concept of a single piece of equipment [5] combining a heat exchanger with a chemical reactor. This has led to the design and development of new intensified heat exchanger-reactors made of different materials, which combine continuous operation with strongly coupled features of heat transfer, hydrodynamics, mixing and reaction. Such designs, derived from the concept of plate heat exchangers [6], involve a stack of plates devoted both to reaction (process plates) and temperature control (utility plates). The number of plates is adjusted according to the application, in order to provide the required residence time. Their design, based on the Process Intensification approach [7], allows continuous operation, a reduction of the physical size of equipment, significant improvements in efficiency, higher yield and purity, a reduction in waste and by-product production, improved selectivity (through plug flow behaviour,

\footnotetext{
* Corresponding author at: Université de Toulouse, INPT, UPS, Laboratoire de Génie Chimique, 4, Allée Emile Monso, F-31432 Toulouse, France.

E-mail address: christophe.gourdon@ensiacet.fr (C. Gourdon).
}

intensified mixing, more isothermal operation and shorter residence time) and both safer and cleaner operations thanks to better temperature control [8-11]. Moreover, their flexible configuration in terms of reaction plates, utility pates, multiple injections points and sensors additions offers the possibility of drastically improving thermal process control and safety [12].

Nowadays, many heat exchanger-reactors ranging from micro to milli-scale are to be found on the market [13], utilising different materials chosen according to their physical and economic properties: raw material price, manufacturing ease, resistance to corrosion, thermal conductivity, transparency, optical features, etc. Based on such considerations, in the more conventional equipment used in the fine chemical or pharmaceutical industry, stainless steel and glass are the most common materials. Thus, many heat exchanger suppliers such as Alfa Laval, Chart [14] and Heatric [15] propose stainless steel based heat exchanger-reactors with various sealing solutions (gasket, brazing, diffusion bounding, etc.). These suppliers also offer other metallic solutions for high corrosion applications for instance Hastelloy, Haynes, Monel or Titanium. In the field of micro-reactors for lab-scale and pilot applications, stainless steel and metals resistant to corrosion are also commonly used (IMM [16], Microinnova [17], Uniqsis). Other metals are also used for specific applications, such as aluminium [18] and copper (Microinnova falling film microreactor).

In spite of its limited heat transfer capacity, glass constitutes an interesting solution for feasibility studies and data acquisition, thanks to the possibilities of visually following the reaction evolution and of easy implementation of on-line analysis. For instance, Corning [19-21] proposes equipment from lab to production scale. At lab-scale, many glass heat exchanger micro-reactors can be 


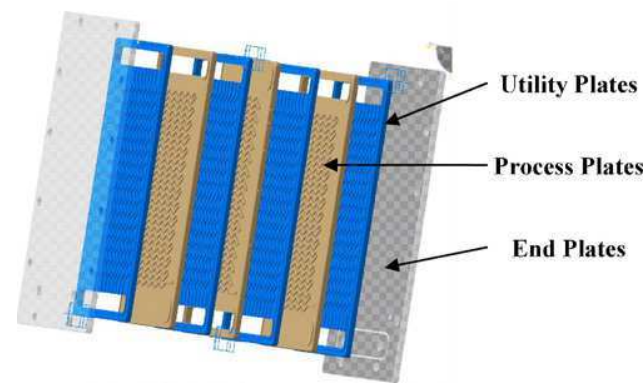

Fig. 1. Scheme of a heat exchanger-reactor.

found: Syrris, Future Chemistry, Chemtrix, Mikroglas [22], Micronit [23], etc. In the context of micro-reactors, other materials can also be found, such as PTFE (Uniqsis, Syrris, Vapourtec [24,25]) which offers similar features in terms of transparency and resistance to corrosion, and PEEK (Uniqsis). Ceramics are also used in order to develop innovative technology, as in the ESK ceramics microreactors [26].

A few examples of equipment combining different materials, in order to benefit from the advantages of each one, are available in literature or on the market. Syrris [27] and Uniqsis propose systems made of different materials (glass, PTFE, and stainless steel), but they can only be assembled in series. The use of different materials in a single system can only be found in academic studies: for instance the hydrolysis of acetic anhydride performed in two micro-reactors in silicon/glass and PDMS [28], the fluorination of toluene [29] performed in a 32-channel gas-liquid reactor built of nickel and stainless steel and in a silicon-based dual-channel gas-liquid micro-reactor.

The present study is built around this concept of hybrid heat exchanger-reactors made of different materials and aims to evaluate the resulting benefits. The use of conventional materials stainless steel and aluminium - is complemented by the use of an innovative material: silicon carbide. This ceramic material presents many advantages from a Process Intensification viewpoint, as it offers high levels of corrosion resistance and high thermal conductivity. The objectives of this work are not only to assess the feasibility and potentialities of new prototypes of heat exchangerreactor but also to evaluate how the materials used drive the performances, in terms of hydrodynamics, heat transfer safety. To achieve this goal, five different heat exchanger-reactor configurations have been investigated: plexiglas/aluminium (which is considered as a reference), full stainless steel, full silicon carbide, silicon carbide/stainless steel and silicon carbide/aluminium in order to examine their respective advantages and drawbacks.

\section{Pilot description}

The present work is based on performance characterisation of heat exchanger-reactors. Such reactors, represented in Fig. 1, consist of an assembly of different types of plates developed from the concept of plate heat exchangers: process plates where the reaction occurs and utility plates in order to control the reactive medium temperature. Each process plate is placed between two utility plates and this assembly of plates is pressed between two end plates.

In the context of the present study, the plates used are manufactured in different materials from a design developed on the basis of previous work carried out at the Laboratoire de Génie Chimique [30]. The process plates design, represented in Fig. 2, consists of a channel of $2 \mathrm{~mm}$-hydraulic diameter (the dimensions of channel are $2 \mathrm{~mm} \times 2 \mathrm{~mm}$ - width $\times$ height), with straight portions and right-angled bends, characteristics of which are described in

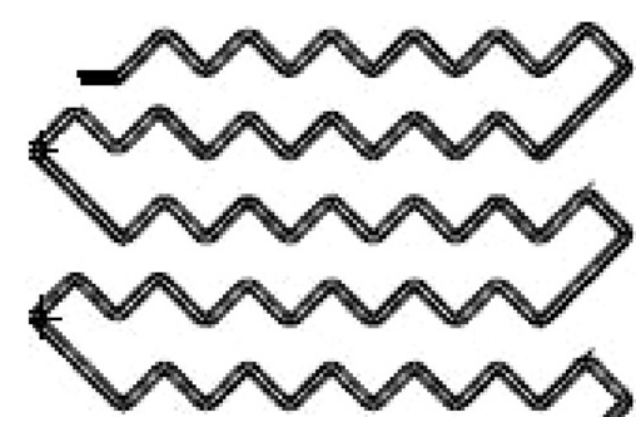

Fig. 2. Design of process plate.

Table 1 . The design and the characteristic dimensions of the channel have been developed in order to offer high mixing and transfer performances (both heat and mass) even for low Reynolds numbers [31]. Two geometries are available for the utility plates. The plates devoted to thermal control consist both of structured plates, with a series of channel of $2 \mathrm{~mm}$-diameter, straight lengths and angled bends, and unstructured ones.

To evaluate the importance of the material used, plates were available in different materials. The process plates could be made of plexiglas, stainless steel or silicon carbide. Different materials could be also used for the utility plates: stainless steel, aluminium or silicon carbide. The final stacking is ensured by stainless steel end plates which offer rigidity and allow feeding lines to be connected (Fig. 3). Thus, with regards to materials, a set of different heat exchanger-reactors can be defined. From an industrial point of view, the choice of the materials will of course be driven by the characteristics of the considered application in terms of exothermy and of corrosion. In the context of the present study, five different heat exchanger-reactors have been defined, as described in Table 2 .

Reactor 1, mixed plexiglas/aluminium (referred as 1-MPA), is considered as a heat exchange reference as it only allows heat to be transferred by convection due to the very low thermal conductivity of the plexiglas process plate. It is an academic reactor since heat exchange performances and corrosion resistance are limited. As it is only involved in characterisation studies (mixing, heat and mass transfer), the setup involves only one plate. Reactor 2 (referred as 2 - Full SS), consists of a full stainless steel heat exchanger-reactor, a classical solution proposed by many equipment suppliers: AlfaLaval, Chart, etc. Reactors 3-5 (referred respectively as 3 - Full SiC,

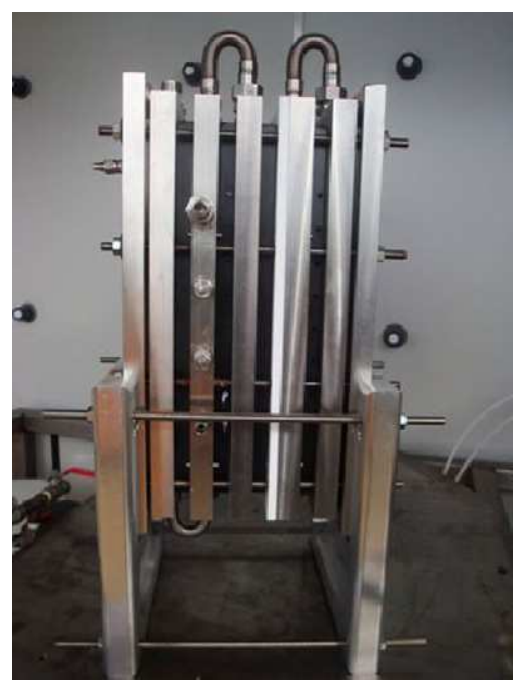

Fig. 3. Example of heat exchanger-reactor: reactor 4-mixed silicon carbide/stainless steel. 
Table 1

Characteristic dimensions of the heat exchanger-reactors.

\begin{tabular}{llll}
\hline & Process plate & Utility Plate \\
\cline { 3 - 4 } & & Structured plate \\
\hline Plate volume $(\mathrm{mL})$ & 11.23 & 49.62 \\
Hydraulic diameter $(\mathrm{mm})$ & 2.03 & 2.03 & 390 \\
Flow area $\left(\mathrm{mm}^{2}\right)$ & 3.69 & 3.69 \\
Developed length $(\mathrm{m})$ & 3.04 & 4.94 & - \\
Radius of curvature $(\mathrm{mm})$ & 1.5 & - & - \\
Straight length $(\mathrm{mm})$ & 6.97 & - & - \\
Angle bend & $90^{\circ}$ & - & - \\
\hline
\end{tabular}

Table 2

Catalogue of HEX reactors.

\begin{tabular}{lllll}
\hline Reactor & $1-$ MPA & $2-$ Full SS & $3-$ Full SiC & 4- MSiCS \\
\hline Process plate material & Plexiglas & Stainless steel & Silicon carbide & Silicon carbide \\
Utility plate material & Aluminium & Stainless steel & Silicon carbide & Stainless steel \\
Process plate $(\mathrm{g})$ & - & 1640 & 865 & 1910 \\
Utility plate $(\mathrm{g})$ & - & 1550 & 782 & 6255 \\
End plate $(\mathrm{g})$ & - & 10,793 & 7139 & 1910 \\
Total mass $(\mathrm{kg})$ & - & 33 & 20 & 2519 \\
\hline
\end{tabular}

Table 3

Advantages and drawbacks of the different materials.

\begin{tabular}{|c|c|c|c|c|c|c|}
\hline Parameters & Plate & 1 - MPA & 2 - Full SS & $3-$ Full SiC & $4-\mathrm{MSiCS}$ & 5 - MSiCA \\
\hline Corrosion resistance & $\begin{array}{l}\text { Utility } \\
\text { Process }\end{array}$ & $\begin{array}{l}\text { Very bad } \\
\text { Very bad }\end{array}$ & $\begin{array}{l}\text { Good } \\
\text { Good }\end{array}$ & $\begin{array}{l}\text { Excellent } \\
\text { Excellent }\end{array}$ & $\begin{array}{l}\text { Good } \\
\text { Excellent }\end{array}$ & $\begin{array}{l}\text { Very bad } \\
\text { Excellent }\end{array}$ \\
\hline Thermal conductivity & $\begin{array}{l}\text { Utility } \\
\text { Process }\end{array}$ & $\begin{array}{l}\text { Very bad } \\
\text { Very bad }\end{array}$ & $\begin{array}{l}\text { Moderate } \\
\text { Bad }\end{array}$ & $\begin{array}{l}\text { Excellent } \\
\text { Excellent }\end{array}$ & $\begin{array}{l}\text { Moderate } \\
\text { Excellent }\end{array}$ & $\begin{array}{l}\text { Good } \\
\text { Excellent }\end{array}$ \\
\hline Relative roughness & $\begin{array}{l}\text { Utility } \\
\text { Process }\end{array}$ & - & Very bad & Excellent & Excellent & Excellent \\
\hline Machinability & $\begin{array}{l}\text { Utility } \\
\text { Process }\end{array}$ & $\begin{array}{l}\text { Good } \\
\text { Good }\end{array}$ & $\begin{array}{l}\text { Moderate } \\
\text { Very bad }\end{array}$ & $\begin{array}{l}\text { Good } \\
\text { Good }\end{array}$ & $\begin{array}{l}\text { Good } \\
\text { Good }\end{array}$ & $\begin{array}{l}\text { Good } \\
\text { Good }\end{array}$ \\
\hline Brazing procedure & $\begin{array}{l}\text { Utility } \\
\text { Process }\end{array}$ & $\begin{array}{l}- \\
-\end{array}$ & Good & $\begin{array}{l}- \\
\text { Good }\end{array}$ & $\begin{array}{l}- \\
\text { Good }\end{array}$ & $\overline{-}_{\text {Good }}$ \\
\hline
\end{tabular}

4 - MSiCS, 5 - MSiCA), are based on the use of silicon carbide process plates, which offer both high resistance to corrosion and high thermal conductivity. The combination of utility plates of different materials for each reactor leads to specific features in terms of heat transfer and safety which are studied in the following sections. Advantages and drawbacks of different materials are detailed in Table 3. Each of reactors used in the present work presents the same design of process plate. Nevertheless, they differ in the design of utility plate and in the manufacturing, stacking and sealing procedures: reactors 1-3 have the same structured utility design and sealing procedures which consist of using o-ring gaskets. Reactors 4 and 5 have a different utility design and the plate stacking is provided by brazing for process plates and gaskets for unstructured utility plates.

As the main difference between these heat exchanger-reactors lies in the materials used and their related physical properties, Table 4 gives a comparison of these properties and more precisely those which influence heat transfer and hydrodynamics: the density, the specific heat, the thermal conductivity, the uniform and relative roughness, the thermometric conductivity and the thermal diffusivity, related by the following equations:

$\varepsilon=\frac{K}{D_{h}}$

$b=\sqrt{\rho \lambda C_{p}}$

$a=\frac{\lambda}{\rho C_{p}}$ where $\varepsilon$ is the relative roughness, $K$ is the equivalent uniform roughness $(\mathrm{m}), D_{h}$ is the hydraulic diameter $(\mathrm{m}), b$ is the thermometric conductivity $\left(\mathrm{J} \mathrm{s}^{-1 / 2} \mathrm{~m}^{-2} \mathrm{~K}^{-1}\right), a$ is the thermal diffusivity $\left(\mathrm{m}^{2} \mathrm{~s}^{-1}\right), \rho$ is the density $\left(\mathrm{kg} \mathrm{m}^{-3}\right), \lambda$ is the thermal conductivity $\left(\mathrm{W} \mathrm{m}{ }^{-1} \mathrm{~K}^{-1}\right)$, and $C_{p}$ is the specific heat $\left(\mathrm{J} \mathrm{kg}^{-1} \mathrm{~K}^{-1}\right)$.

A specific pilot plant has been used for the characterisation of heat exchanger-reactors (Fig. 4).

This pilot plant allows inlets and outlets of the reactor to be controlled in terms of flow rate, pressure and temperature. In this way, the utility fluid (water or bath liquid) is introduced into the reactor from a process thermostat (Lauda Integral XT 150) through an electromagnetic flow-meter. Two dosing lines are available for the circulation of the reactants, both including a gear pump and a mass flow-meter (Micro Motion Coriolis based). These feed lines ensure reactants introduction in the reactor at a given temperature defined by process thermostats. Reactants are initially stocked in storage tanks and collected in another one at reactor outlet.

Temperature measurements (PT100) are set up at the inlet and outlet of the dosing and utility lines. Moreover, 12 thermocouples are positioned along the reactor process plates (maximally 8 per plate) in order to provide an internal temperature profile. Pressure measurements (relative pressure sensors) are set up on each line. Moreover, a differential pressure sensor $(\Delta P)$ could be positioned between each inlet and outlet of the heat exchanger-reactor to provide an accurate value of pressure drops. All measurements are collected by an on-line data record system. 


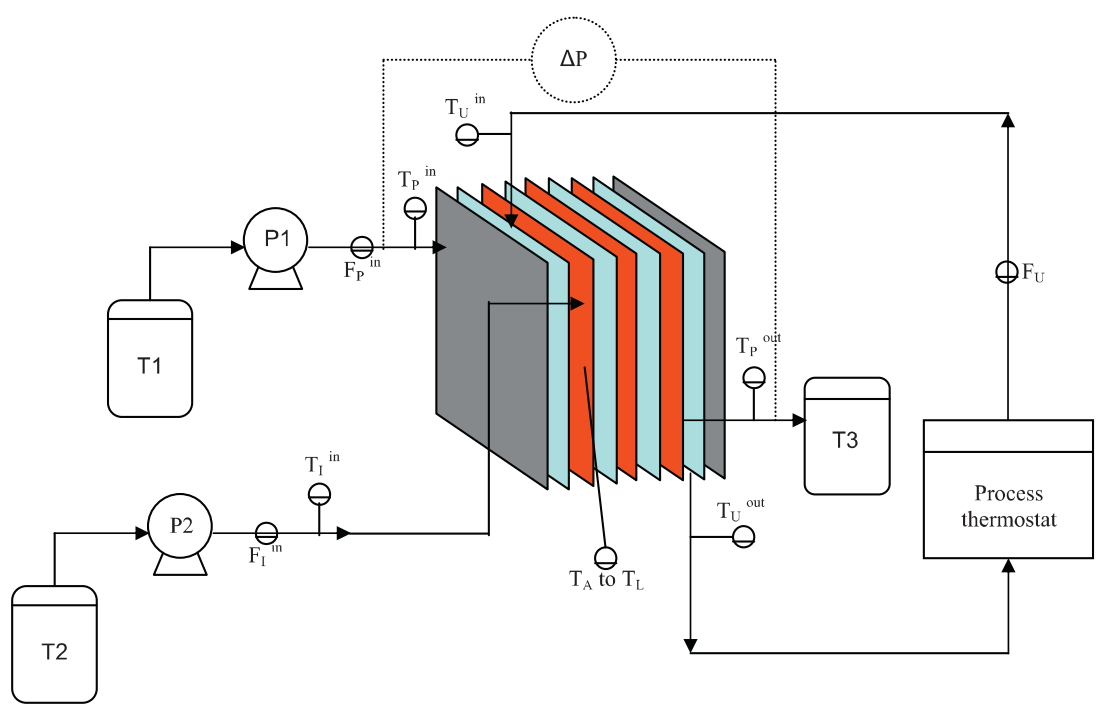

Fig. 4. Pilot plant and measurements.

\section{Influence of material on pressure drop}

Heat exchanger-reactors offer specific designs of channels to improve mixing and transfer (heat and mass), particularly at low flowrates to comply with residence time constraints. These designs, generally based on the alternation of straight lines, corners, widening, narrowing and mixing elements (see Fig. 2), are important pressure drop promoters. The present study aims at characterising the influence of the process-plate material on the pressure drop of such a design of channel. The design of channel presented in Fig. 2 and manufactured in plexiglas, stainless steel and silicon carbide, has been used to perform this comparison.

In the first part of the study, we have fully characterised the pressure drops related to the channel design using a reference plate made of silicon carbide, a material with a low roughness value (see Table 4). The pressure drops have been experimentally measured thanks to a differential pressure sensor between the inlet and the outlet of the reactors, for fluids of different viscosities and for various flowrates (from 0 to $20 \mathrm{~kg} \mathrm{~h}^{-1}$ ). Water, acetone and mixture of silicon oils which offer a range from 0.32 to $55\left(10^{-3} \mathrm{~Pa} \mathrm{~s}\right)$, have been used to achieve this goal.

From the pressure drops measurements, the Darcy coefficient [32] can be computed:

$\Delta P=D a \frac{L}{D_{h}} \frac{\rho u^{2}}{2}$

where $L$ is the channels length (m), Da is the Darcy coefficient (or Darcy friction factor), $D_{h}$ is the channels hydraulic diameter $(\mathrm{m}), \rho$ is the density of the liquid phase $\left(\mathrm{kg} \mathrm{m}^{-3}\right)$, and $u$ is the mean linear velocity of the liquid phase $\left(\mathrm{m} \mathrm{s}^{-1}\right)$.

The Darcy coefficient is an important experimental parameter that helps to indicate over what range of Reynolds numbers flow regimes become fully developed.

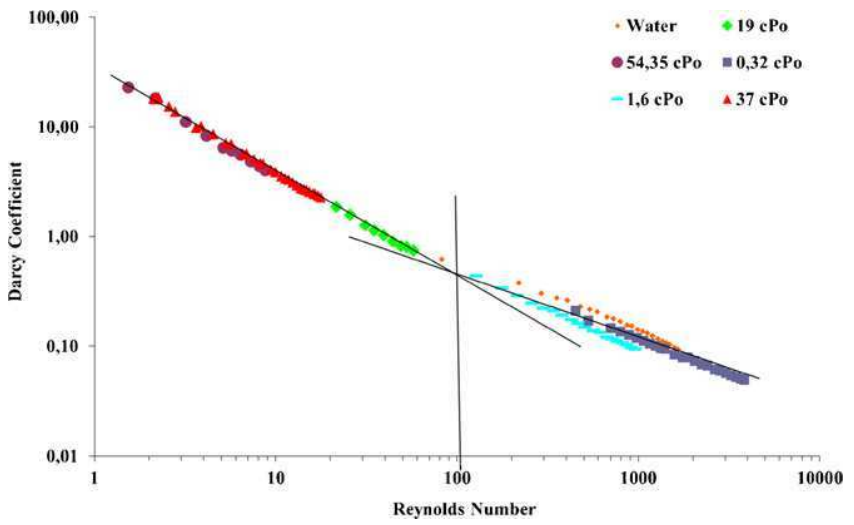

Fig. 5. Experimental Darcy number versus Reynolds number.

The evolution of Darcy number with Reynolds number, given in Fig. 5, highlights the presence of two main flow regimes, one at low Reynolds (laminar behaviour) and one at high Reynolds (transitional and turbulent behaviour). It is important to notice that the channel design concerned leads to a shift in the classical Reynolds domain for the different flow regimes. In fact, the design allows a turbulent-like behaviour to be obtained for Reynolds numbers higher than 100 , while with straight channels the transition is expected to occur for Reynolds numbers higher than 2100 [32]. Such behaviour is of great interest from a Process Intensification viewpoint, as it promotes some flow instabilities which are favourable to mixing and heat transfer performances at lower Reynolds numbers and consequently for longer residence times.

Since, in a channel presenting angle bends, pressure drops depends on flow perturbations which appear at lower Reynolds numbers than those classically found in straight channels, it is

Table 4

Physical properties of materials.

\begin{tabular}{|c|c|c|c|c|c|c|c|}
\hline Material & $\begin{array}{l}\text { Density } \\
\left(\mathrm{kg} \mathrm{m}^{-3}\right)\end{array}$ & $\begin{array}{l}\text { Specific } \\
\text { heat } \\
\left(\mathrm{J} \mathrm{kg}^{-1} \mathrm{~K}^{-1}\right)\end{array}$ & $\begin{array}{l}\text { Thermal } \\
\text { conductivity } \\
\left(\mathrm{W} \mathrm{m}^{-1} \mathrm{~K}^{-1}\right)\end{array}$ & $\begin{array}{l}\text { Equivalent uniform } \\
\text { roughness } \\
\left(10^{3} \mathrm{~mm}\right)\end{array}$ & $\begin{array}{l}\text { Relative } \\
\text { roughness } \\
\left(10^{3}\right)\end{array}$ & $\begin{array}{l}\text { Thermometric } \\
\text { conductivity } \\
\left(\mathrm{J} \mathrm{s}^{-1 / 2} \mathrm{~m}^{-2} \mathrm{~K}^{-1}\right)\end{array}$ & $\begin{array}{l}\text { Thermal } \\
\text { diffusivity } \\
\left(10^{6} \mathrm{~m}^{2} \mathrm{~s}^{-1}\right.\end{array}$ \\
\hline Plexiglas & 1200 & 1500 & 0.2 & 9 & 4.5 & 600 & 0.1 \\
\hline Stainless steel & 7900 & 500 & 16 & 10 & 5 & 7950 & 4.1 \\
\hline Aluminium & 2700 & 900 & 237 & 2 & 1 & 24,000 & 98 \\
\hline Silicon Carbide & 3200 & 750 & 170 & 0.05 & 0.025 & 20,200 & 71 \\
\hline
\end{tabular}




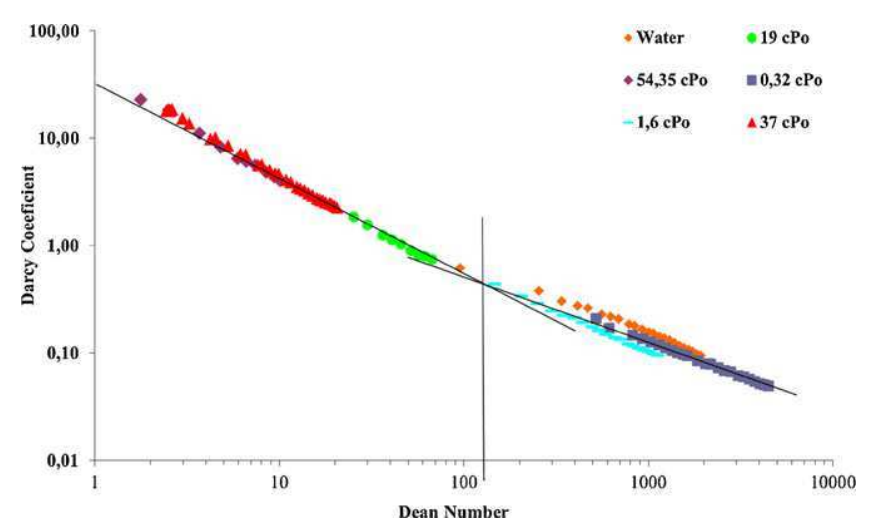

Fig. 6. Experimental Darcy number versus Dean number

appropriate to refer to another dimensionless number, called the Dean number, defined by:

$D e=\operatorname{Re} \sqrt{\frac{D_{h}}{R_{C}}}$

where De is the Dean number, Re is the Reynolds number, $D_{h}$ is the hydraulic diameter (m), and $R_{c}$ is the radius of curvature (m).

The evolution of the Darcy number with Dean number, given in Fig. 6, highlights the change in flow regime which appears for a critical Dean number of 150: the usual value beyond which the Dean vortices are expected to appear. According to Anxionnaz [33], the change of flow regime is reached for a critical Dean number in the range of $100-250$, the exact value depending on the geometry of channel (number of angle bends, radius of curvature, straight length, ....). Under the same conditions as our own, i.e., an identical channel geometry, Anxionnaz finds a Dean number of 160 , which is very close to our value.

For a given plate design, the influence on pressure drop of the three materials has been investigated, using three different plates, made of silicon carbide, plexiglas and stainless steel. A comparison of the pressure drops with each material has been carried out for experiments using water, with flow rates varying from 0 to $12 \mathrm{~kg}$ per hour (Fig. 7).

As observed in Fig. 7, even though the roughness clearly has an influence on pressure drop, the material, as anticipated, is of little influence as only slight variations are observed. Silicon carbide appears to give the least pressure drop while plexiglas appears to give the most greatest. This variation cannot be due to measurement inaccuracy: the precision of the differential pressure sensor is in the range of $\pm 0.2 \%$. Considering that relative roughness affects drastically the pressure drops [34,35], we have checked

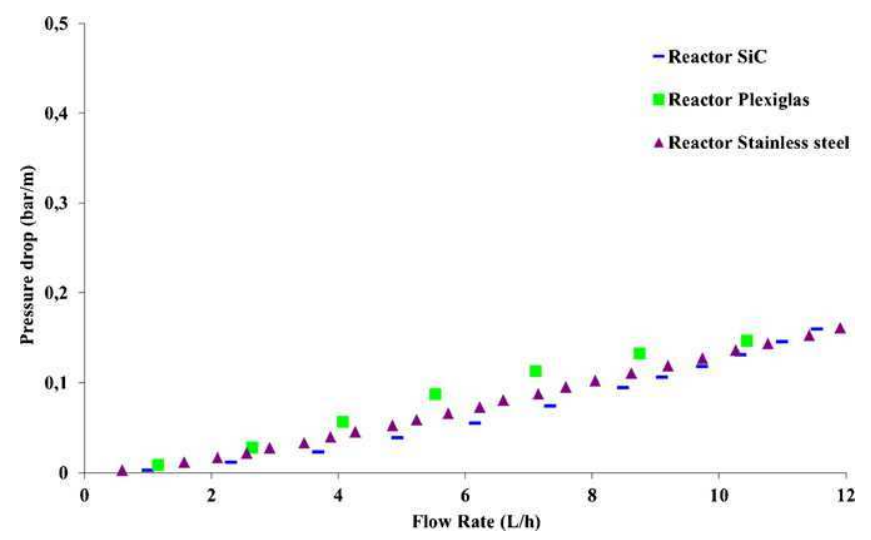

Fig. 7. Pressure drop for HEX reactors. if the experimentally observed variations could be linked to this parameter. Literature shows that pressure drop increases with relative roughness [32] and so theoretically the pressure drop should grow with silicon carbide, plexiglas and stainless steel (see Table 4). Experimentally, plexiglas thus shows a greater pressure drop than expected (see Fig. 7). This could be explained by the manufacturing procedure which involved mechanical surfacing of the channel.

In conclusion, with regards to pressure drop, the choice of material is of little influence. This result is important as it invalidates the rules established for straight duct channels for which pressured drops are directly governed by relative roughness according to a linear law. The study also suggests that manufacturing procedures adopted to finish surfaces are more of greater influence than the nature of the material. In view of the wide variety of these procedures (depending on the material and equipment supplier see Section 1), it now appears to draw difficult any conclusions regarding the influence of the material itself.

\section{Influence of material on heat transfer}

Since these heat exchanger-reactors are based on the concept of plate heat exchangers, the thermal aspects are represented by three coupled phenomena characterised by different kinetics: forced convection, conduction and thermal capacitance. Each phenomenon provides its own contribution to the thermal features (heat transfer performances, thermal capacitance) which drive the thermal control and intrinsic safety of the reactor. In the present section our objective is to estimate and compare these effects and relate them to the nature and properties of the materials used.

\subsection{Heat transfer performance}

The choice of material is important from a safety point of view. Specifically, it is necessary to choose a material which can quickly absorb heat released by exothermic reactions, thereby confining any risk. This ability is governed by the thermometric conductivity and the thermal diffusivity, defined in Table 4 . The thermometric conductivity determines the initial rate at which material exchanges heat with the adjacent medium. The higher the thermometric conductivity, the greater the ability of the material to impose its temperature on the reactive medium. The thermal diffusivity is the parameter determining the rate of spread of heat through the material. The comparison of the different values gathered in Table 4 highlights the higher efficiency of the silicon carbide (and also obviously of the aluminium).

In the present studies, the thermal characterisation of the systems is obtained from a classical cooling method which allows heat transfer to be measured. The heat transfer is estimated from the temperature gradients measured at reactor inlets and outlets between a hot and a cold fluid. To this end, flow-meters and temperature sensors were implemented on the pilot device in order to record on a computer the evolution of the internal energy of each fluid. Tests were performed using water as hot and cold fluid. Hot water (about $80^{\circ} \mathrm{C}$ ) was introduced as the process fluid with a flow rate of $1-12 \mathrm{~L} \mathrm{~h}^{-1}$, while the utility water was introduced at $5^{\circ} \mathrm{C}$ with a flow rate of $100 \mathrm{Lh}^{-1}$. At steady state, these experiments allow the overall heat transfer coefficient to be estimated, according to the following simple balance equation:

$\frac{U A}{V}=\frac{Q}{V \Delta T_{m l}}$

where $U$ is the overall heat transfer coefficient $\left(\mathrm{W} \mathrm{m}^{-2} \mathrm{~K}^{-1}\right), A$ is the exchange surface area $\left(\mathrm{m}^{2}\right), V$ is the volume between the inlet of the reactor and the thermocouple in question $\left(\mathrm{m}^{3}\right), Q$ is the global heat 


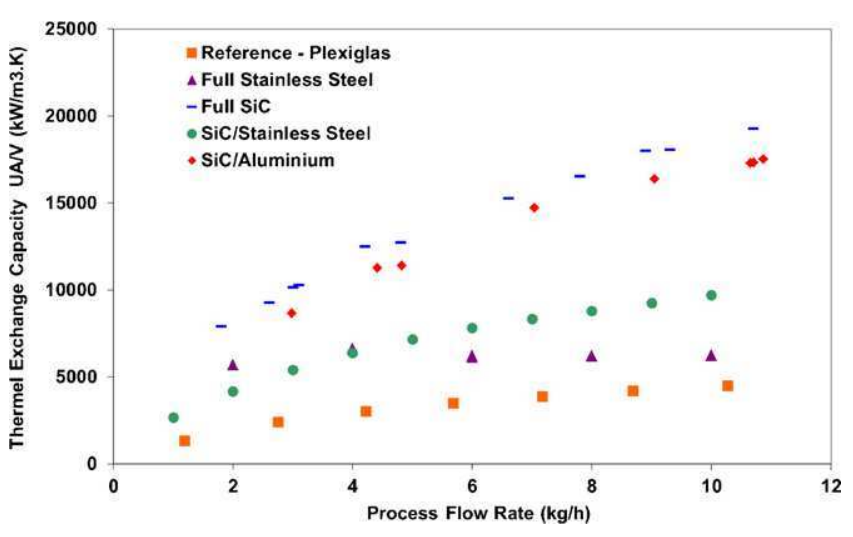

Fig. 8. Thermal exchange capacity.

exchange (W), and $\Delta T_{m l}$ is the logarithmic temperature difference with

$\Delta T_{m l}=\frac{\left(T_{p}^{\text {in }}-T_{u}^{\text {in }}\right)-\left(T_{p}^{\text {out }}-T_{u}^{\text {out }}\right)}{\ln \left(\left(T_{p}^{\text {in }}-T_{u}^{\text {in }}\right) / T_{p}^{\text {out }}-T_{u}^{\text {out }}\right)}$

Since flows inside the reactor are considered as co-current, where $T_{p}^{i n}$ is the process temperature at the inlet $\left({ }^{\circ} \mathrm{C}\right), T_{p}^{\text {out }}$ is the process temperature at the outlet $\left({ }^{\circ} \mathrm{C}\right), T_{u}^{i n}$ is the utility temperature at the inlet $\left({ }^{\circ} \mathrm{C}\right), T_{u}^{\text {out }}$ is the utility temperature at the outlet $\left({ }^{\circ} \mathrm{C}\right)$ and

$Q=F_{p} C_{p_{p}}\left(T_{p}{ }^{\text {in }}-T_{p}{ }^{\text {out }}\right)$

where $F_{p}$ is the process flowrate $\left(\mathrm{kg} \mathrm{h}^{-1}\right)$, and $C_{p_{p}}$ is the process specific heat $\left(\mathrm{J} \mathrm{kg}^{-1} \mathrm{~K}^{-1}\right)$.

The global heat exchange is only considered on the process fluid side, from thermocouples where the thermal efficiency is greater than $90 \%$, i.e. the first and sometimes second thermocouple inside the reactor. We assume that the utility heat exchanged is the same as on process side, thermal losses being considered negligible in view of the limited surface area between the process inlet and the first thermocouple. The thermal exchange capacity, obtained from the product of the global heat transfer coefficient and the ratio between the surface area and the fluid volume, is represented in Fig. 8 for the different reactors as a function of the process flow rate (utility flow rate being kept constant at $100 \mathrm{~kg} \mathrm{~h}^{-1}$ ).

As the thermal conductivity of plexiglas is very low (see Table 4), the thermal exchange in the plexiglas heat exchanger-reactor is assumed to result only from convection. This reactor can thus be considered as a purely convection reference case. In the full stainless steel heat exchanger-reactor, the thermal exchange capacity appears constant whatever the flow rate. Such behaviour reveals predominantly conductive heat transfer. In this case, therefore, thermal exchange results from both convection and conduction, with a conduction limiting at high flow rates, leading to the observed the constant heat transfer capacity. Such a feature is very interesting from a safety point of view, particularly in cases of failure of the process fluid circulation system (decrease or disturbance of the flow rate), when the reactor will continue to absorb or release heat at the same level.

In silicon carbide based reactors (full silicon carbide, with stainless steel and with aluminium), the thermal exchange presents a convective profile which increases with flow rate. Nevertheless, the values of heat transfer capacity are much higher than in the plexiglas reference case. In silicon carbide reactors, convection and conduction are coupled in a such way that the behaviour appears convective, but with performance increasing with thermal conductivity: full silicon carbide and mixed silicon carbide/aluminium exhibit the same heat transfer capacity but a higher capacity than that of mixed stainless steel. For mixed stainless steel such behaviour allows the thermal capacity to be increased by a factor of 2 with respect to the plexiglas/aluminium reference, while for full silicon carbide and mixed silicon carbide/aluminium this factor is 4 .

Silicon carbide based reactors definitely offer high heat transfer coefficients and thereby promising perspectives with regard to highly exothermic reactions. The value of this coefficient is, however, highly dependant of the choice of transfer area. In the present study, because of the importance of conductive effects, this area is assumed to be composed of the whole surface in contact with the process fluid (i.e. the wetted surface) and not only the area between the process fluid channel and the utility fluid as classically used for convective estimation.

To further emphasize the importance of the material properties, Table 5 compares the average heat transfer capacity of the silicon carbide heat exchanger-reactors used in the present study with those of commercial continuous reactors. It is important to note that all the reactors presented have been characterised in our lab according to the same methodology.

\subsection{Thermal capacitance}

Heat exchanger-reactors offer an intrinsically safe feature as described by Benaissa et al. $[9,10]$. This feature, related to thermal capacitance, is mainly explained by the important mass of the equipment relative to the reactive medium volume: for instance, the Alfa Laval ART Plate Reactor 37 made of stainless steel is about $100 \mathrm{~kg}$ for a reactive volume of about $150 \mathrm{~mL}$ (10 reactive plates). In cases of disturbances or failures of temperature control, this important thermal capacitance allows temperature deviation and thermal runaway to be limited.

The thermal capacitance is therefore a key characteristic of heat exchanger-reactors and is mainly related to the mass and the specific heat of the materials used. The amount of utility fluid present in the reactor (from 50 to $400 \mathrm{~mL}$ according to the type of plate, see Table 1 ) is very small and has been neglected in front of the mass of reactor material. The present section aims at emphasizing how materials influence the thermal capacitance and how thermal capacitance can be compatible with high heat transfer capacities. To this end, the different kinds of reactor described in Section 2 have been thoroughly studied.

In order to evaluate the thermal capacitance of the considered heat exchanger-reactors, it is necessary to determine the mass and the properties of the different elements of the structure which could promote energy dissipation. Thus, the heat released by the reaction is evacuated through the plate wall between process and utility fluids and through the process plate itself, then through the utility fluid and the utility plate. The thermal environment of the process fluid thus consists of the following elements:

- the process plates,

- the plate walls,

- the utility fluid,

- the utility plates,

- and in some cases, the end plates of the reactor.

The thermal environment can be characterised by the addition of the contributions of each element and the related material, according to a methodology given by Benaïssa et al. [9] based on the definition of the adiabatic coefficient. Nevertheless, as it is very difficult to estimate each contribution, experiments were performed in order to estimate the thermal capacitance.

A shut down of utility flow was realised in order to simulate a failure on the utility fluid system. At the beginning of the experiments, the process and utility flowrates were constant and 


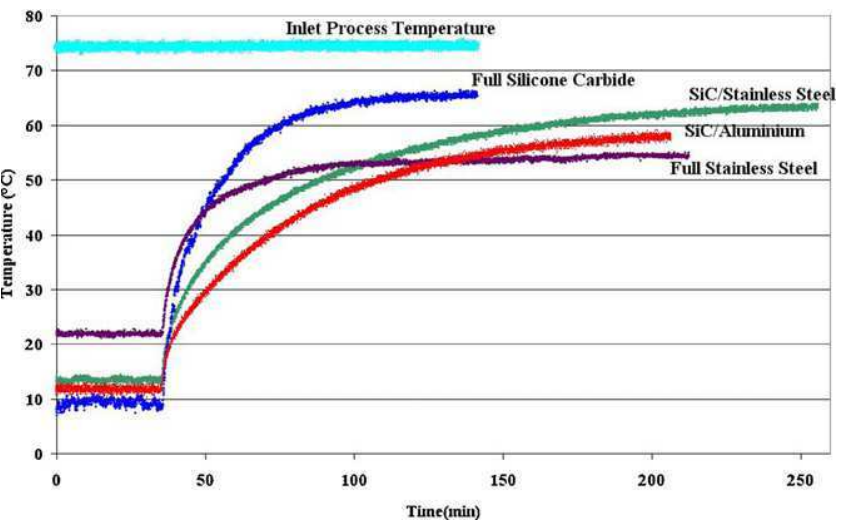

Fig. 9. Comparison of temperature variation at the first thermocouple for different reactors.

respectively fixed at $5.20 \mathrm{~kg} \mathrm{~h}^{-1}$ and $100 \mathrm{~kg} \mathrm{~h}^{-1}$ with inlet temperatures of respectively $75^{\circ} \mathrm{C}$ and $5^{\circ} \mathrm{C}$. After reaching a steady state representative of normal operating conditions, a cooling failure was caused by stopping the utility fluid flow. Evolutions of temperatures of the first and last thermocouples in the different reactors as a function of time were then recorded and represented in Figs. 9 and 10. When this kind of failure occurs, the process fluid must not be stopped in order to continue to favour mixing and thermal transfer. In an industrial case, reactive mixture must be replace by a solvent to avoid accumulation of heat and risks of thermal runaway.

Three important phases are noted:

- Phase 1 (0-35.5 min): the process fluid temperature is stable. The steady state is reached.

- Instant $t=35.5 \mathrm{~min}$ : the utility fluid is stopped.

- Phase 2 (>35.5 min): an increase of the process fluid temperature related to thermal capacitance is observed, due to the absence of cooling.

According to Figs. 9 and 10, temperature curves show the same tendency at both the first and last thermocouples for each reactor. The process temperature never reaches the inlet process temperature of $74.5^{\circ} \mathrm{C}$ because of global large thermal losses on the whole reactor. These thermal losses represent a loss of $10^{\circ} \mathrm{C}$ in the case of based silicon carbide reactors and a loss of $25^{\circ} \mathrm{C}$ in the case of the full stainless steel reactor.

In order to estimate the thermal capacitance, each reactor has been considered as consisting of two blocks: one consisting of the channel in which the reaction occurs, the other one being the whole reactor mass, including utility fluid and material. This simplified

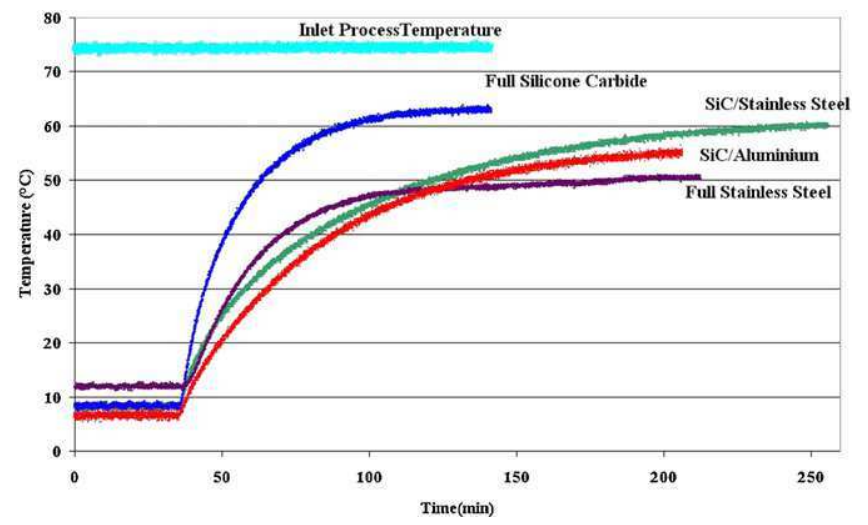

Fig. 10. Comparison of temperature variation at the last thermocouple for different reactors. 


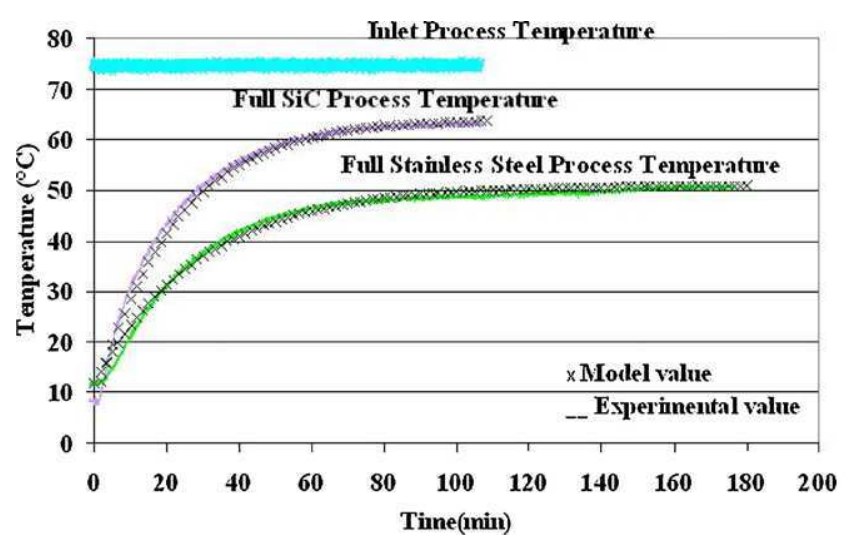

Fig. 11. Model of temperature variation at the last thermocouple for the full silicon carbide and full stainless steel reactors.

concept leads to the following Eqs. (7) and (8) where the identified parameters are: $m_{m} \cdot C_{p_{m}}$ and $U^{\prime} A^{\prime}$.

$$
\begin{aligned}
& m_{p} C_{p_{p}} \frac{d T_{p}}{d t}=F_{P} C_{p_{p}}\left(T_{p}^{i n}-T_{p}\right)+U A\left(T_{m}-T_{p}\right) \\
& m_{m} C_{p_{m}} \frac{d T_{m}}{d t}=U A\left(T_{p}-T_{m}\right)+U^{\prime} A^{\prime}\left(T_{e x t}-T_{m}\right)
\end{aligned}
$$

where $m$ is the mass $(\mathrm{kg}), C_{p}$ is the specific heat $\left(\mathrm{J} \mathrm{kg}^{-1} \mathrm{~K}^{-1}\right), T$ is the temperature $(\mathrm{K}), T_{p}^{i n}$ is the inlet process temperature and $T_{p}^{i n}=$ $74.5^{\circ} \mathrm{C}, T_{\text {ext }}$ is the temperature of the external environment and $T_{\text {ext }}=18^{\circ} \mathrm{C}, F_{p}$ is the process fluid flowrate $\left(\mathrm{kg} \mathrm{s}^{-1}\right), U$ is the heat coefficient transfer $\left(\mathrm{W} \mathrm{m}^{-2} \mathrm{~K}^{-1}\right)$ and $A$ is the surface area $\left(\mathrm{m}^{2}\right)$.

With in subscribed: $m$ for the material and $p$ for the fluid process.

Combining both Eqs. (7) and (8), Eq. (9) can be obtained:

$$
\begin{aligned}
& \frac{m_{m} C_{p_{m}} m_{p} C_{p_{p}}}{U A} \frac{d^{2} T_{p}}{d t^{2}}+\left(m_{m} C_{p_{m}}+\frac{m_{m} C_{p_{m}} F_{p} C_{p_{p}}}{U A}+m_{p} C_{p_{p}}\right. \\
& \left.+\frac{U^{\prime} A^{\prime} F_{p} C_{p_{p}}}{U A}\right) \frac{d T_{p}}{d t}=\left(-F_{p} C_{p_{p}}-U^{\prime} A^{\prime}-\frac{U^{\prime} A^{\prime} F_{p} C_{p_{p}}}{U A}\right) T_{p} \\
& +\left(F_{p} C_{p_{p}} T_{p_{i n}}+U^{\prime} A^{\prime} T_{e x t}+\frac{U^{\prime} A^{\prime} F_{p} C_{p_{p}}}{U A} T_{p_{i n}}\right)
\end{aligned}
$$

The term $\left(d^{2} T_{p} / d t^{2}\right)$ can be neglected because it is an infinitely bare value.

With this hypothesis, Eq. (9) becomes:

$$
\begin{aligned}
& \left(m_{m} C_{p_{m}}+\frac{m_{m} C_{p_{m}} F_{p} C_{p_{p}}}{U A}+m_{p} C_{p_{p}}+\frac{U^{\prime} A^{\prime} F_{p} C_{p_{p}}}{U A}\right) \frac{d T_{p}}{d t} \\
& =\left(-F_{p} C_{p_{p}}-U^{\prime} A^{\prime}-\frac{U^{\prime} A^{\prime} F_{p} C_{p_{p}}}{U A}\right) T \\
& +\left(F_{p} C_{p_{p}} T_{p_{i n}}+U^{\prime} A^{\prime} T_{e x t}+\frac{U^{\prime} A^{\prime} F_{p} C_{p_{p}}}{U A} T_{p_{i n}}\right)
\end{aligned}
$$

Making use of Eq. (10), the material thermal capacitance $\left(m_{m}\right.$ $C_{p_{m}}$ ) can be estimated and the thermal losses $\left(U^{\prime} A^{\prime}\right)$ evaluated. Fig. 11 represents an example of the experimental and simulated results: temperature profiles of the process fluid for the last thermocouples of the full silicon carbide reactor and the full stainless steel reactor. The parameters of each reactor are summarized in Table 6.

A simplified conceptual view of the reactor has obviously been adopted in order to model the behaviour of the different reactors in the event of an incident. This modelization takes into account the evolution of the process temperature $\left(T_{p}\right)$ and the overall mean temperature of the environment of the process channel $\left(T_{m}\right)$.

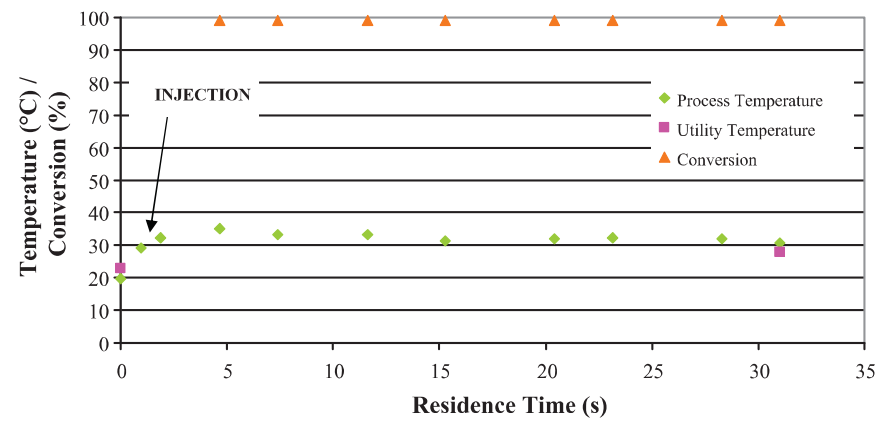

Fig. 12. Temperature along $\mathrm{SiC} /$ stainless steel heat exchanger-reactor.

Despite the use of a simplified approach, if the thermal capacitance $\left(m_{m} \cdot C_{p_{m}}\right)$ of the reactors is known, the model allows the correct prediction of the dynamic behaviour when a disturbance occurs.

An evaluation based on the characterisation heat transfer performance and thermal capacitance indicates that the hybrid reactors appear to present a number of advantages. They offer a good compromise that allows both enhanced temperature control (active safety) and improved passive safety (with high thermal capacitance). In particular the use of silicon carbide for the process plates and aluminium for the utility plates represents the best solution. In addition the light weight of this combination makes for easier handling.

\section{Case-study: an exothermic reaction in mixed silicon carbide-stainless steel heat exchanger-reactor}

To emphasize the benefits of a hybrid design of heat exchangerreactor in regard to the materials used, a reactive application case has been studied. Both thermal performances and inertia, linked to the use of silicon carbide for the reactive side and to stainless steel for the utility one, are highlighted by carrying out an instantaneous and highly exothermic reaction. The mixed silicon carbide/stainless steel prototype, described in Section 2, has been used for this purpose.

A pharmaceutical application has been chosen for which the productivity constraints comply with the prototype flow rate. This application presents instantaneous kinetics and strong exothermy ( $\Delta H=-200 \mathrm{~kJ} \mathrm{~mol}^{-1}$ and about $100^{\circ} \mathrm{C}$ adiabatic temperature rise for the concentrations considered) driven by a competitive and parallel reaction scheme:

$\mathrm{A}+\mathrm{B} \rightarrow \mathrm{C}+\mathrm{D}$

$\mathrm{B}+$ Water $\rightarrow \mathrm{D}$

Eq. (11) is the main reaction which gives the desired product $C$. Eq. (12) is a by-reaction which has to be minimized and leads to co-product $D$. A is introduced via the main feed line and B is introduced in excess via the secondary feed line (Fig. 4). Utility fluid, which is water at $25^{\circ} \mathrm{C}$ and operates both as heating (to pre-heat reactants) and cooling fluid (to maintain an isothermal profile during reaction), is supplied a few minutes before the beginning of an experiment in order to thermostat the reactor. Reactant $A$ is then first introduced into the reactor, which has already been filled with distilled water (solvent). Next, reactant B is introduced. The steady state is reached when all flow rates, pressures and temperatures appear stable on the on-line data record system. An on-line analysis system (Raman spectroscopy developed by Kaiser Optical Systems) has also been implemented on the reactor to follow the conversion and estimate kinetics.

Fig. 12 shows an example of the temperature profile along the heat exchanger-reactor, measured by internal thermocouples, which emphasizes the enhanced heat transfer performance. During 
Table 6

Thermal capacitance of each reactor.

\begin{tabular}{|c|c|c|c|c|c|}
\hline & & 2 - Full SS & 3 - Full SiC & 4-MSiCS & 5 - MSiCA \\
\hline \multirow{2}{*}{ Theoretical value } & $\left(m \cdot C_{p}\right) \operatorname{th}\left(\mathrm{J} \mathrm{K}^{-1}\right)$ & 17,000 & 11,700 & 34,500 & 25,900 \\
\hline & $m(\mathrm{~kg})$ & 20 & 34 & 53 & 38 \\
\hline \multirow{3}{*}{ Model for last thermocouple } & $m \cdot C_{p}\left(\mathrm{JK}^{-1}\right)$ & 17,000 & 8000 & 21,000 & 23,000 \\
\hline & $U^{\prime} A^{\prime}\left(\mathrm{WK}^{-1}\right)$ & 5.0 & 1.4 & 1.8 & 2.8 \\
\hline & $m \cdot C_{p} /\left(m \cdot C_{p}\right)$ th & 1.00 & 0.68 & 0.61 & 0.88 \\
\hline
\end{tabular}

this experiment, both process fluids circulate inside the reactor. The main and secondary process line flow rates are respectively fixed at $3.7 \mathrm{~kg} \mathrm{~h}^{-1}$ and $0.8 \mathrm{~kg} \mathrm{~h}^{-1}$ (about $31 \mathrm{~s}$ of residence time in the reactor). The utility flow rate is set up at $45 \mathrm{~kg} \mathrm{~h}^{-1}$. It is interesting to note that in spite of the high exothermy (for the reactant concentrations used, the adiabatic temperature rise is about $100^{\circ} \mathrm{C}$ ) and the fast kinetics (about 98\% of conversion achieved in less than $5 \mathrm{~s}$ ), the heat transfer performances provide a quasi-isothermal behaviour. The first temperature corresponds to the pre-heating of reactant $A$. The injection takes place between the first and the second thermocouple. The second thermocouple thus represents the reactive medium temperature after the injection. The reactive medium temperature increases by just a few degrees (less than $5^{\circ} \mathrm{C}$ ) when the reaction occurs. Nevertheless, as the reaction is quite instantaneous and the heat exchange very efficient, the temperature quickly reaches steady state. After $5 \mathrm{~s}$ and until the reactor outlet, the reactant medium temperature is controlled at about $30^{\circ} \mathrm{C}$.

The intrinsically safe feature and thermal capacitance of the reactor have also been validated from a similar experiment with the same reactants. During this experiment, both process fluids circulate inside the reactor: the main and secondary process line flow rates are respectively fixed at $3.7 \mathrm{~kg} \mathrm{~h}^{-1}$ and $0.8 \mathrm{~kg} \mathrm{~h}^{-1}$. The utility flow rate is set up at $45 \mathrm{~kg} \mathrm{~h}^{-1}$. To study thermal capacitance, the temperature variations are followed in time at two different points of the reactor: just after the injection of reactant $\mathrm{B}$ at a location which constitutes the hottest point of the reactor and at the outlet of the reactor. At steady state and due to the enhanced thermal performances (see Fig. 13) the temperatures at these points are virtually the same at about $30^{\circ} \mathrm{C}$. In order to simulate a cooling system failure and evaluate the resulting temperature change, the utility flow was stopped at $t=52 \mathrm{~min}$. For $16 \mathrm{~min}$ (from $t=42 \mathrm{~min}$ to $68 \mathrm{~min}$ ), the exothermic reaction continued without external cooling control. Both the temperature just after injection and the temperature at the reactor outlet, increase due to the absence of cooling. The reactive medium temperature just after injection increases faster than that at the reactor outlet. Indeed, as the reaction is almost instantaneous, close to the injection point, the reaction occurs releasing heat, whereas up to the reactor outlet, the reactive medium

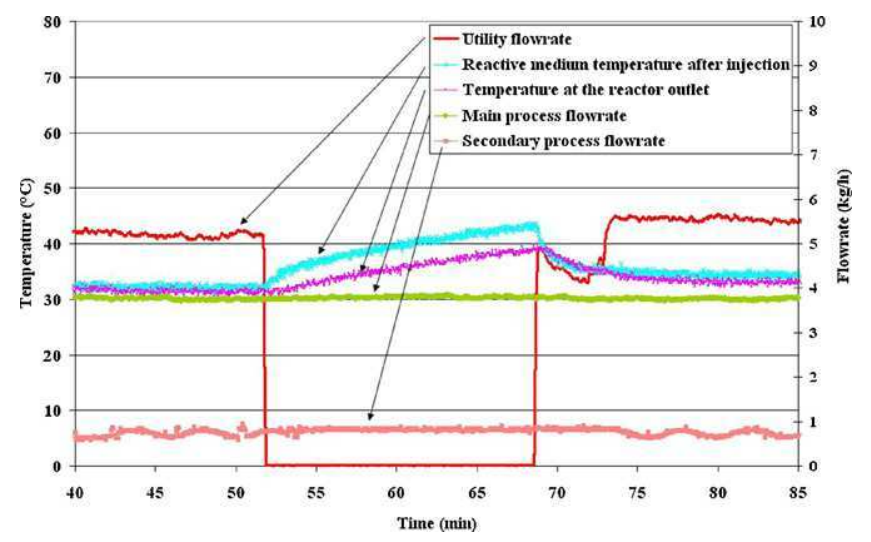

Fig. 13. Evolution of the temperature at the first thermocouple when failure occurs circulation corresponds to residence time without heat released. At $t=68 \mathrm{~min}$, the utility fluid is reintroduced inside the reactor at $45 \mathrm{~kg} \mathrm{~h}^{-1}$ and the temperature immediately decreases until the steady state is reached. The trend of curves presented in Fig. 13 highlights the strong thermal capacitance (the reactive medium temperature only increases of $12^{\circ} \mathrm{C}$ at most during $16 \mathrm{~min}$ ) and also the high temperature control (reactive medium needs only $47 \mathrm{~min}$ to reach the nominal steady state after the failure).

\section{Conclusion}

Heat exchanger-reactors represent a promising alternative new way of transposing a chemical reaction from a batch to a plugflow continuous processing mode. In fact, such systems combine continuous operation with strongly coupled features of heat transfer, hydrodynamics, mixing, mass transfer and reaction. Moreover, thanks to its smaller size and volume, this kind of equipment minimizes the consequences in the case of hazard release. The present study on such systems shows the impact and influence of materials on the thermal performance and on the safety aspects. The thermal study underlines through the high global heat exchange coefficient and heat exchange capacity, the strong heat transfer performances of the silicon carbide based heat exchanger-reactors (full silicon carbide, mixed silicon carbide and stainless steel or aluminium). By comparison with commercial equipment, reactors involving silicon carbide process plates are found to be 6-20 times more efficient in terms of heat transfer. The present work further shows that these enhanced heat transfer performances are not obtained to the detriment of the thermal capacitance and so the intrinsically safe feature of heat exchanger-reactors. In fact, by combining materials like aluminium or stainless steel with silicon carbide it is possible to comply with both heat exchange and thermal capacitance requirements. Such features linked to the mixing of materials have been successfully validated in a case study based on an instantaneous and highly exothermic reaction. In this case, the hybrid reactor considered (silicon carbide with stainless steel) exhibits isothermal behaviour with a strong thermal capacitance. Moreover, dynamics experiments also underline the high control of the reactive medium temperature and the safety feature offered by this kind of equipment.

\section{Acknowledgements}

The authors want to gratefully acknowledge Boostec Industries for the providing equipment and particularly, Marc Ferrato and Patrick Chereau for their technical support and scientific discussions.

\section{References}

[1] C.H. Philips, G. Lauschke, H. Peerhossaini, Intensification of batch chemical processes by using integrated chemical reactor-heat exchangers, Applied Thermal Engineering 17 (1997) 809-824.

[2] C. Tsouris, P. Costas, V. Joseph, Process intensification - has its time finally come? Chemical Engineering Progress 99 (10) (2003) 50-55

[3] J.A. Moulijn, A. Stankiewicz, j. Grievink, A. Gorak, Process intensification and process system engineering: a friendly symbiosis, Computer and Chemical Engineering 32 (2008) 3-11. 
[4] J.C. Charpentier, In the frame of globalization and sustainability process intensification, a path to the future of chemical and process engineering (molecules into money), Chemical Engineering Journal 134 (2007) 84-92.

[5] A.M. Edge, I. Pearce, C.H. Philips, Compact heat exchangers as chemical reactors of process intensification (PI), BHR Group, Process Intensification (1997) $175-189$.

[6] L. Prat, A. Devatine, P. Cognet, M. Cabassud, C. Gourdon, S. Elgue, F. Chopard, Performance evaluation of a novel concept open plate reactor applied to a highly exothermic reactions, Chemical Engineering \& Technology 28 (9)(2005) 1028-1034.

[7] A.I. Stankiewicz, J.A. Moulijn, Process Intensification: transforming chemical engineering, Chemical Engineering Process (2000) 22-34.

[8] J.C. Etchells, Process intensification safety pros and cons, Process Safety and Environmental Protection 83 (B2) (2005) 85-89.

[9] W. Benaïssa, N. Gabas, M. Cabassud, D. Carson, S. Elgue, S. Demissy, Evaluation of an intensified continuous heat-exchanger reactor for inherently safer characteristics, Journal of Loss Prevention in the Process Industries (2008) 1-9.

[10] W. Benaïssa, S. Elgue, N. Gabas, M. Cabassud, D. Carson, M. Demissy, Dynamic behaviour of a continuous heat-exchanger/reactor after flow failure, International Journal of Chemical Reactor Engineering 6 (A23) (2008) 1-19.

[11] D. Reay, The role of process intensification in cutting greenhouse gas emissions, Applied Thermal Engineering 28 (2008) 2011-2019.

[12] S. Haugwitz, P. Hagander, T. Norén, Modeling and control of a novel heat exchange reactor the open plate reactor, Control Engineering Practice 15 (2007) 779-792.

[13] Z. Anxionnaz, M. Cabassud, C. Gourdon, P. Tochon, Heat exchangers/reactors (HEX reactors): concepts, technologies: state-of-the-art, Chemical Engineering and Processing 47 (12) (2008) 2029-2050.

[14] C.H. Philips, K.T. Symonds, Development of a novel integrated chemical reactor - heat exchanger, Available from: www.pinetwork.org/pubs/ bhrpaper1/bhrpaper1_abst.htm (March 2010), 1997, pp. 1-15.

[15] X. Li, T. Smith, D. Kininmont, S.J. Dewson, Materials for nuclear diffusionbonded compact heat-exchangers, in: International Congress on Advances in Nuclear Power Plants, Tokyo, Japan, May 10-14, 2009.

[16] B. Bromley, V. Hessel, A. Renken, L. Kiwi-Minsker, Sandwich reactor for heterogeneous catalytic processes: $\mathrm{N}_{2} \mathrm{O}$ decomposition as a case study, Chemical Engineering \& Technology 31 (8) (2008) 1162-1169.

[17] D. Kirschneck, G. Tekautz, Integration of a microreactor in an existing production plant, Chemical Engineering \& Technology 30 (3) (2007) 305-308.

[18] Z. Ni, E.G. Seebauer, R.I. Masel, Effects of microreactor geometry on performance: differences between Posted Reactors and Channel Reactors, Industrial and Engineering Chemistry Research 44 (2005) 4267-4271.

[19] P. Barthe, C. Guermeur, O. Lobet, M. Moreno, P. Woehl, D.M. Roberge, N. Bierler, B. Zimmermann, Continuous multi-injection reactor for multipurpose production - part I, Chemical Engineering \& Technology 31 (8) (2008) 1146-1154
[20] D.M. Roberge, N. Bieler, M. Mathier, M. Eyholzer, B. Zimmermann, P. Barthe, C. Guermeur, O. Lobet, M. Moreno, P. Woehl, Development of an industrial multi-injection microreactor for fast and exothermic reactions - part II, Chemical Engineering \& Technology 31 (8) (2008) 1155-1161.

[21] Corning ISPD Europe, Corning glass materials for industrial applications, Filtration \& Separation $30(6)$ (1993) 500.

[22] T.R. Dietrich, A. Freitag, R. Scholz, Production and characteristics of microreactor made from glass, Chemical Engineering \& Technology 28 (4) (2005) 1-7.

[23] S. Mukherjee, M.K. Hatalis, M.V. Kothare, Water gas shift reaction in a glass microreactor, Catalysis Today 120 (2007) 107-120

[24] M. Baumann, I.R. Baxendale, L.J. Martin, S.V. Ley, Development of fluorination methods using continuous-flow microreactors, Tetrahedron 65 (2009) 6611-6625.

[25] I.R. Baxendale, S.V. Ley, A.C. Mansfield, C.D. Smith, Multistep synthesis using modular flow reactors: Bestmann-Ohira reagent for the formation of alkynes and triazoles, Angewandte Chemie 48 (2009) 4017-4021.

[26] F. Meschke, G. Riebler, V. Hessel, J. Shürer, T. Baier, Hermetic gas-tight ceramic microreactor, Chemical Engineering \& Technology 28 (4) (2005) $465-473$.

[27] P. Kunding, The future of organic synthesis, Science 314 (5798) (2006) 430-431.

[28] F. Ladeveze, K. Loubière, J. Aubin, D. Fletcher, C. Xuereb, Etude de microreacteurs: influence des conditions hydrodynamiques sur le taux de conversion d'une réaction chimique, Récents Progrès en Génie des Procédés, vol. 92, Editions Lavoisier, 2005, pp. 1-8.

[29] N. De Mas, A. Günther, T. Kraus, M.A. Schmidt, K.F. Jensen, Scaled-out multilayer gas-liquid microreactor with integrated velocimetry sensors, Industrial and Engineering Chemistry Research 44 (2005) 8997-9013.

[30] Z. Anxionnaz, Etude de l'influence de la géométrie des canaux sur les performances d'un réacteur/échangeur, Ph.D. thesis, Institut National Polytechnique de Toulouse, Toulouse, 2009.

[31] B. Thonon, P. Mercier, Flow Structure, Thermal, and Hydraulic Performances of Compact Geometries Used as Integrated Heat-Exchanger Reactor, BHR Group, 1999.

[32] L.F. Mody, Friction factors for pipe flow, Transaction of the ASME 66 (1944) 641.

[33] S.G. Kandlikar, D. Schmitt, A.L. Carrano, J.B. Taylor, Characterization of surface roughness effects on pressure drop in single-phase flow in minichannels, Physics of Fluids 17 (10) (2005) 1-11.

[34] G. Croce, P. D'agaro, C. Nomino, Three-dimensional roughness effect on microchannel on heat transfer and pressure drop, International Journal of Heat and Mass Transfer 50 (2007) 5249-5259.

[35] Z. Anxionnaz, M. Cabassud, C. Gourdon, P. Tochon, Transposition of an exothermic reaction from a batch reactor to an intensified continuous one, Heat Transfer Engineering 31 (9) (2010) 788-797 